\title{
Linguistic Categories and the Syntax-Semantics Interface: Evaluating Competing Approaches
}

\author{
Gisa Rauh
}

\section{Introduction}

Words have meanings, which provide the basis for semantic categories, and words occur in particular positions in sentences, which categorizes them syntactically. What I will be concerned with in this paper is how the semantic and the syntactic properties of words are related or - to be more precise - how linguists assume that these are related and describe this relationship. In other words, the crucial questions are how various linguists describe the interface between the syntactic and semantic categories of words and how plausible their positions are. It is the goal of this paper to provide an answer to these questions.

According to the traditional view, words are specified for syntactic and semantic properties in their entries in the lexicon. However, more recently this view has been criticized. One central argument is that various languages allow the same form with the same meaning to be used either as a verb or as a noun, for example walk, drink or sleep in English, indicating that syntactic categorization is fixed not in the lexicon but rather in the syntax.

In what follows I will first take a look at how the relationship between the syntactic and semantic properties of words is described in selected approaches that conform to the traditional view. These include two representatives of the generative-interpretive approach, the Standard Theory and the Theory of Principles and Parameters, followed by Head-Driven Phrase Structure Grammar and 
Construction Grammar. After briefly discussing the general characteristics of the interface conception in these approaches - including a discussion of the criticism leveled at them - I will turn to others which claim that syntactic specification is not part of lexical entries but rather a matter of syntactic (or morphological) structural environments. Here I will take a look at Neo-Construction Grammar and Role and Reference Grammar. Subsequently, the plausibility of the interface conceptions of these various approaches will be investigated. The paper will end with a discussion of controversial views on cross-linguistic differences concerning the noun-verb distinction and the consequences these can have for interface conceptions.

\section{Generative-interpretative approaches}

In this section, aspects of the description of the interface between syntactic and semantic properties of words in the Standard Theory (henceforth ST, cf. Chomsky 1965) and in the Theory of Principles and Parameters (henceforth PPT, cf. e. g. Chomsky 1981, Chomsky \& Lasnik 1993) will be considered.

The grammatical model of the ST consists of a generative syntactic component, the interpretive components of semantics and phonology and a lexicon. The lexicon is considered to be a list of lexical entries which specify all the idiosyncratic properties of a given language. It is language-specific.

Lexical entries for words are claimed to include a phonological representation (a phonological matrix), intrinsic semantic properties and syntactic properties. Of these Chomsky himself only specifies syntactic properties, namely a categorial specification, e.g. N, V, A, etc., strict subcategorization determining the number and syntactic category of complements, e. g. -NP, -NP PP, and selection restrictions specifying intrinsic semantic features of the complement(s) and the subject. The following provides an example:

(1) ( sincerity, $[+\mathrm{N},+$ Det,-- Count, + Abstract, ...])

(frighten, $[+\mathrm{V},+-\mathrm{NP},+[+$ Abstract $]$, Aux - Det [+Animate $],+$ Object-deletion, ... $]$ )

(Chomsky 1965: 107)

It should be noted that one phonological matrix may be associated with more than one set of syntactic properties and/or with more than one set of intrinsic 
semantic properties, resulting in various readings (cf. e. g. Katz \& Fodor 1963). In these cases there is more than one lexical entry.

Syntactically, the ST distinguishes two levels of representation, deep structure and surface structure, which are derived by phrase-structure rules and transformational rules respectively. The syntactic categories of words, i. e. their distribution, are then described by the interaction of lexical-syntactic properties with phrase-structure rules and transformational rules.

The semantics of sentences in this framework, as worked out by Katz \& Fodor (1963), interprets deep structures via projection rules, which start out with the lexically specified semantic properties of the words, which are inserted into deep structures and then amalgamated to form larger semantic units.

In this approach then, the idea is that the relationship between syntax and semantics at word level is described by means of lexical entries, which therefore can be identified as representing the interface between the two. Syntactic categories are determined on the basis of shared syntactic properties of various lexical entries and semantic categories on the basis of their shared semantic properties.

Like the ST, the PPT distinguishes between a lexicon and grammar in the narrow sense, the latter here called the 'computational system'.

As in the ST, the lexicon of the PPT is a list of lexical entries which specify all the idiosyncratic properties of a language, and it is language-specific. Here as well, the lexical entries for words at least are claimed to combine phonological, semantic and syntactic specifications.

Whereas the phonological and semantic specifications are basically as in the ST, syntactic specifications here include a categorial specification based on feature combinations of $[ \pm \mathrm{N}]$ and $[ \pm \mathrm{V}]$, with $[+\mathrm{N}]$ - according to Chomsky \& Lasnik (1993: 517) - expressing the "traditional substantive" and [+V] the "predicate", an argument structure specifying how many arguments an item licenses and what semantic roles they receive, strict subcategorization if this cannot be predicted by general principles, and Case-assignment properties. The feature combinations $[ \pm \mathrm{N}]$ and $[ \pm \mathrm{V}]$, which describe nouns as $[+\mathrm{N},-\mathrm{V}]$, verbs as $[-\mathrm{N},+\mathrm{V}]$, adjectives as $[+\mathrm{N},+\mathrm{V}]$ and prepositions as $[-\mathrm{N},-\mathrm{V}]$, are more flexible than the corresponding category labels $\mathrm{N}, \mathrm{V}, \mathrm{A}$ and $\mathrm{P}$ in that they allow for generalizations over particular features. Thus, for example, $[-\mathrm{N}]$-categories are identified as Case-assigners in English and $[+\mathrm{N}]$-categories as Case-receivers. 
The PPT distinguishes four levels of representation: d-structure, s-structure, logical form (LF) and phonological form (PF). Of these the first two are clearly syntactic representations, whereas LF and PF are characterized as interfaces to other, 'external' systems with which they interact, LF as an interface to the conceptional-intentional system C-I and PF to the articulatory-perceptual system A-P.

The computational system consists of various general and parametrized principles such as the Projection Principle or the Principle of Full Interpretation and those of the modules of X-bar Theory, Theta Theory and Case Theory, and the operation Move $\alpha$. Starting with lexical representations, sentence structures are then derived by interaction between the various principles, which finally identifies the syntactic categories of words.

As in the ST, the idea in this framework is that the syntactic and semantic categories of words are intimately related since syntactic and semantic properties are claimed to be combined in their lexical representations, which therefore, in principle, function as an interface between the two. However, except for argument structures, no suggestions are made concerning the kind of semantic representations, and their interpretation is not discussed either. All that is said is that LF interacts with the 'external' conceptual-intentional system, 'conceptual' in this case referring to semantic issues and 'intentional' to pragmatic issues.

\section{Head-Driven Phrase Structure Grammar}

Just like the two approaches considered above, Head-Driven Phrase Structure Grammar (henceforth HPSG) distinguishes between a lexicon and grammar. However, the lexicon is not just a list of lexical entries which specify idiosyncratic properties of words but consists of lexical entries with various degrees of generality determined by constraints related to a hierarchy of lexeme types, by additional constraints - e. g. the Specifier-Head Agreement Constraint or the Case Constraint - and lexical rules, e. g. inflectional rules. Lexical entries of type word, the building blocks of syntax, are the most elaborated and specific lexical entries. There are numerous variants of HPSG. The characterization below relates to the classical version developed by Pollard \& Sag (1994), which forms the basis for subsequent variants and overviews. ${ }^{1}$

1 Cf. e. g. Sag et al. (2003), Levine \& Meurers (2006) and Müller (2010, chap. 8). 
The information provided in lexical entries is modeled by a system of typed (or 'sorted') feature structures, which are described by feature descriptions with the format of attribute-value matrix (AVM) diagrams expressing constraints on well-formed feature structures. AVM diagrams of words include descriptions of a phonological matrix, of syntactic properties such as categorial specifications and specifications of grammatical arguments, including inflectional specifications, as well as of semantic (referential) properties such as the word's contextindependent contribution to the semantic interpretation of a phrase and - where necessary - context dependent (pragmatic) information relating to indexical properties, presuppositions or conventional implicatures (cf. Pollard \& Sag 1994: 22). In addition there are tags, represented as boxed numerals, indicating structure sharing of attributes or values. The example in Figure 1, which presents a lexical entry of the finite verb gives, illustrates this.

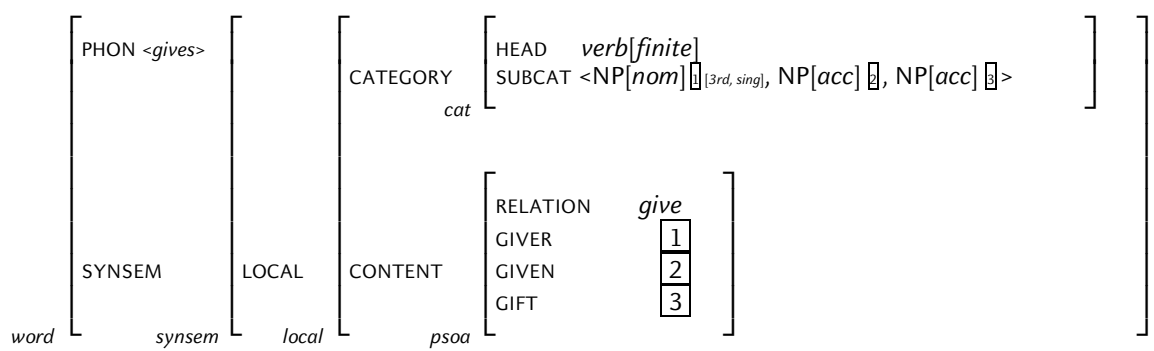

Figure 1: Lexical entry of the finite verb gives, adapted from Pollard \& Sag (1994)

The AVM diagram describes a feature structure of type word with the attributes PHON(OLOGY) and SYN(TAX)SEM(ANTICS). The PHON value gives indicates the phonological matrix of the word. The SYNSEM attribute includes a complex of integrated syntactic and semantic information. Its value is a structured object of type synsem with the attribute LOCAL, whose value, loc(al), contains the information relevant in local contexts, ${ }^{2}$ described in Figure 1 by the attributes CATEGORY and CONTENT. ${ }^{3}$ The CATEGORY value is an object of type cat(egory) which contains the attributes HEAD and SUBCAT(EGORIZATION). The HEAD

2 In addition, the value of synsem may contain the attribute NONLOCAL, in this case describing information relevant to the analysis of unbounded dependency phenomena.

3 CONTEXT is a possible additional attribute describing pragmatic properties, which play no role here. 
value specifies for gives the part of speech verb with the feature finite. The SUBCAT value specifies a list of three NPs describing constraints on well-formed grammatical arguments of the verb. The NPs are marked by tags, 1, 2 and 3 . NP 1 is specified for the case feature nom(inative) and in addition for the person feature $3 r d$ and the number feature sing(ular). The other two NPs are both specified for the case feature acc(usative). The CONTENT value is a structured object of type psoa ('parametrized state of affairs') with the attributes RELATION, GIVER, GIVEN and GIFT. The RELATION value give describes the kind of state of affairs that the word give refers to. The attributes GIVER, GIVEN and GIFT describe the roles of the participants in this state of affairs. Their values are specified by the tags 1, 2 and 3 respectively, which correspond to the tags of the argument NPs, with identical tags indicating structure sharing. This describes that the first argument NP in the SUBCAT list and the GIVER role share the same structure as their common value, and so do the second NP and the GIVEN role and the third NP and the GIFT role.

The sample AVM diagram of a lexical entry in Figure 1 illustrates that in HPSG syntactic and semantic properties of words, represented by the attributes CATEGORY and CONTENT and specified by their values, are described as one complex of integrated linguistic information represented by the attribute SYNSEM|LOC.

The syntax of HPSG consists of principles such as the Head Feature Principle (which requires that the HEAD value of any sign is always structure-shared with that of its phrasal projections), the Valence Principle (which replaces the earlier Subcategorization Principle ${ }^{4}$ ), or the Immediate Dominance (ID) Principle and schemata representing the Head-Specifier Rule, the Head-Complement Rule, the Head-Modifier Rule and finally Linear Precedence Rules. The semantics of HPSG includes the Semantic Compositionality Principle and the Semantic Inheritance Principle. The principles and schemata or rules interact with the features in the feature descriptions of words to derive feature descriptions of phrases and sentences with integrated syntactic and semantic properties. There is just one representation containing phonological, syntactic, semantic and information structural constraints at the same time. This is in line with the general claim of HPSG that language is a system of signs intimately relating form and meaning (cf. e. g. Pollard \& Sag 1987: 15 ff., 31; cf. also Rauh 2010: 169 ff.).

4 This is discussed by Pollard \& Sag (1994: 348). 
In this approach then, just as in the previously discussed approaches, syntactic and semantic properties of words are determined by the information spelled out in lexical entries. Unlike these approaches, however, lexical semantic properties are not accessed for the purpose of interpreting independently derived syntactic structures but they are integrated with syntactic properties in lexical entries as well as in syntactic structures yielding single integrated syntactic-semantic representations. As a consequence, in one respect, no interfaces between syntactic and semantic categories of words can be identified because syntactic and semantic properties are described as sharing feature structures and thus forming one integrated complex of linguistic information. In another respect, however, it could be claimed that it is the feature structures of the attribute CATEGORY and of the specifications of its value on the one hand shared with the feature structures of the attribute CONTENT and of the specifications of its value on the other - as described in the lexical entries of words - that function as interfaces between these types of categories. ${ }^{5}$

\section{Construction Grammar}

There are several variants of Construction Grammar. The one considered here is the version developed by Fillmore and Kay (henceforth $\mathrm{CxG}$, cf. e. g. Fillmore \& Kay 1993, Kay \& Fillmore 1999, Fillmore 1999, Kay 2002).

$\mathrm{CxG}$ does not strictly distinguish between lexicon and grammar. Representations of lexical items and phrases or sentences have the same construction format and differ only with respect to their internal complexity. As in HPSG, representations of lexical items can be of various degrees of generality, the more specific ones here being related to the more general ones by particular lexical constructions (e.g. the Pluralization Construction, the Count $\gg$ Mass Construction, cf. Figure 6 below) or by grammatical constructions (e.g. Linking Constructions). And as in HPSG, lexical items as well as phrases and sentences are described by means of feature descriptions consisting of attribute-value matrices.

Feature descriptions of words include a description of the lexeme and - in fully specified lexical entries - the form of the lexeme (e.g. write vs. writes), syntactic properties including categorial specifications such as $n, v$, etc. and morphological

5 Cf. Kuhn (2007) for a discussion on interfaces in HPSG and other constraint-based theories. 
properties such as specifications for plural, tense or voice, specifications of maximality (of projections) and lexicality and particular syntactically relevant specifications such as 'proper' in the context of $n$. In addition they include semantic properties such as the conceptual or notional specifications 'configuration' (cnfg), 'boundedness' (bounded) and 'number' (num) in the context of $n,{ }^{6}$ the specification of conceptual frames or scenes evoked by verbs, for example, read, put or shout, and the specification of the number of participants involved in particular frames, i. e. two participants in the case of read, three in the case of put and one in the case of shout. Furthermore, valence properties are specified, including the specification of the syntactic category of valence elements (e. g. np), their semantic value, which is unified with a frame-specific participant (expressed e.g. by $\# 1[\ldots])$, the specification of the grammatical function of valence elements (e.g. gf $\operatorname{subj}(\mathrm{ect}))$ and the specification of the theta-role of valence elements (e.g. $\theta$ $\exp ($ eriencer)).

Of the valence properties only the specifications of the theta-roles are part of the general minimal valence entry (e. g. Figure 4). The specifications of grammatical functions and syntactic categories of theta-roles, which are part of fully specified lexical entries (e. g. Figure 5), are the result of the interaction of an inventory of theta-frames determining possible combinations of theta-roles as well as a distinguished argument role, the subject principle and linking constructions. The latter in addition determine voice properties. Figures 2 to 5 represent examples of lexical entries taken from Fillmore \& Kay (1993).

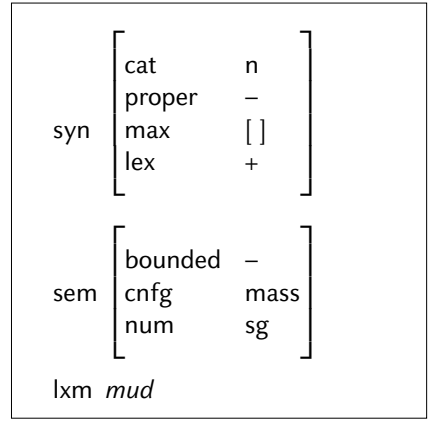

Figure 2: Mass noun (ibid.: 3.6)

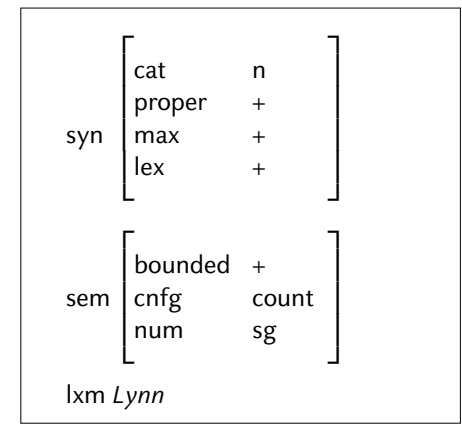

Figure 3: Proper noun (ibid.: 3.6)

6 According to Fillmore \& Kay, 'configuration', 'boundedness' and 'number' are attributes representing the three dimensions of semantic variation which apply to lexical nouns and nominal constructions (cf. Fillmore \& Kay 1993: 3.1 ff.). 


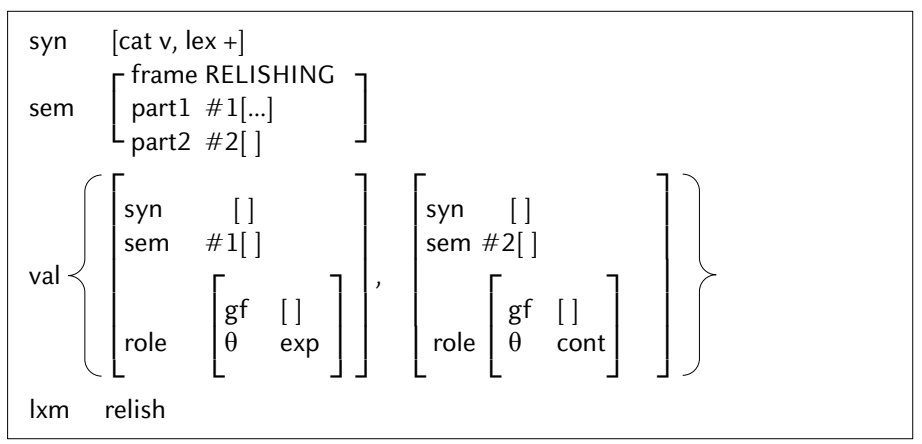

Figure 4: Minimal entry (ibid.: 5.1)

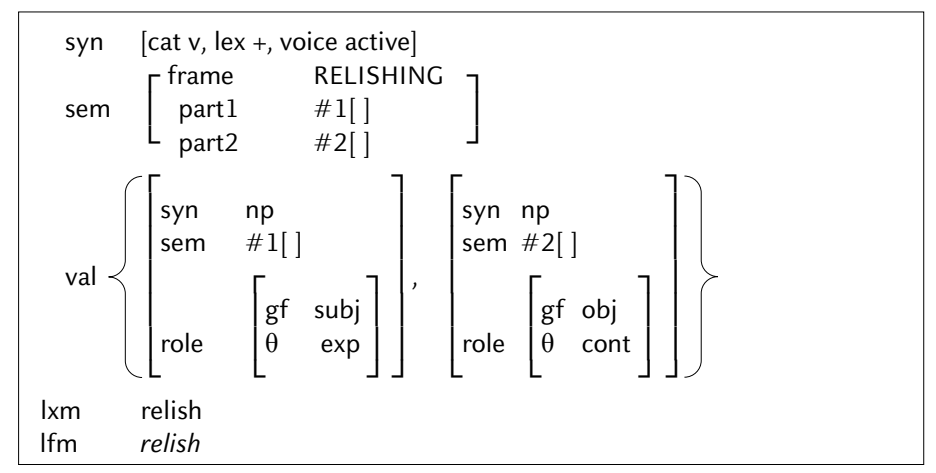

Figure 5: Fully specified entry (ibid.: 5.1)

The fact that lexical items specified as count nouns may be used as mass nouns and vice versa and that proper nouns may be used as count nouns is described by means of particular lexical constructions such as the Count $\gg$ Mass Construction, shown in Figure 6.

In $\mathrm{CxG}$ phrases and sentences are licensed by the unification of fully specified lexical entries with grammatical constructions of various kinds, such as the Left Isolate Construction, the Subject-Predicate Construction, the Verb Phrase Construction, the Modified Nominal Construction, the Determination Construction, Coinstantiation Constructions or Ordering Constructions and their interaction with general principles such as the principles of instantiation and semantic integration. 


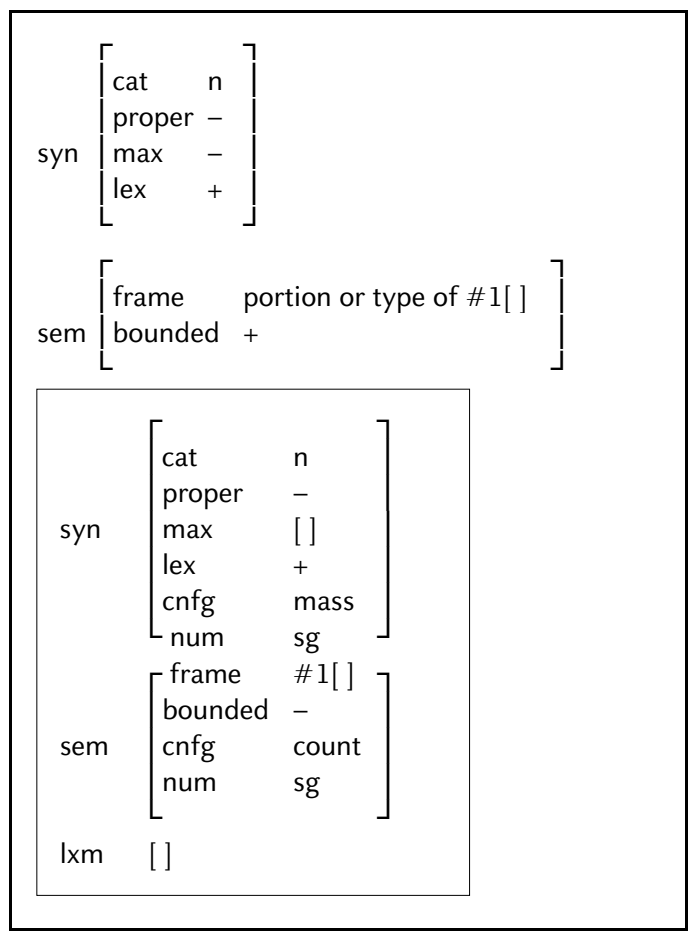

Figure 6: Count $\gg$ Mass Construction (ibid.: 3.28)

As in the previously discussed approaches, the syntactic and semantic categories of words in Fillmore and Kay's version of $\mathrm{CxG}$ are determined by syntactic and semantic properties specified in their lexical entries. Different syntactic and semantic properties result in different lexical entries. As opposed to the approaches discussed in section 2, but to a certain extent similar to the HPSG approach characterized in section 3 , the role of the interface between syntactic and semantic categorization in this approach is played by their corresponding representations (cf. syn and sem in Figures 2, 3 and 6, and in addition by syn, sem and the role of valence elements in Figures 4 and 5).

\section{Intermediate considerations}

So far, four different approaches with different specifications of the syntactic and semantic properties of words have been considered. These different feature 
specifications as such would no doubt be worth more detailed discussion. In this context, however, I will concentrate on what these approaches have in common.

In all of them the syntactic and semantic properties of words are specified or are claimed to be specified - in their lexical entries, implying that the semantic and syntactic properties are lexically specified and represent two sides of one and the same thing. The syntactic specification in each case includes a specification of what is known as a part of speech, such as a noun or verb. It also includes contextual syntactic properties described as strict subcategorization, selection restrictions, syntactic argument structure or syntactic valence.

Specifying syntactic properties like these in lexical entries has been criticized on various grounds. One is that in many languages, including English, the same phonological form with more or less the same meaning ${ }^{7}$ can represent different syntactic categories, for example walk, boat, form, fringe or dog, which can be used as nouns or as verbs. Furthermore, many forms can be used with various and sometimes unexpected argument structures or valences. An impressive example of this is given by Clark \& Clark (1979: 803): ${ }^{8}$

(2) a. The fire stations sirened throughout the raid.

b. The factory horns sirened midday and everyone stopped for lunch.

c. The police sirened the Porsche to a stop.

d. The police car sirened up to the accident.

e. The police car sirened the daylights out of me.

Providing each phonological form with all its potential categorial specifications and argument structures or valences would result in listing a number of lexical entries for each form which some linguists consider uneconomic or even redundant and therefore unnecessary.

Another criticism is that parts of speech are not universal and therefore the syntactic categoryhood of lexical items in many languages cannot be identified in isolation but only in the context of phrases or sentences. ${ }^{9}$ This has been claimed

7 'More or less' here is intended to express the fact that the meanings are closely related and yet different in that one of them is verbal and the other one nominal. This difference is not without consequences for the approaches discussed in the following, as will be shown below.

8 This example is also quoted by Borer (2003: 40), but with slight differences.

9 Note that this criticism overlooks the fact that parts of speech as such do not represent syntactic categories, which will be discussed in section 8.1. 
by, among others, Swadesh (1939) for Nootka, by Hengeveld (1992), Bhat (2000) and Hengeveld \& Rijkhoff (2005) for Mundari, by Mosel \& Hovdhaugen (1992) for Samoan, by Schachter (1985), Gil (1995) and Himmelmann (2008) for Tagalog and by Van Valin (e. g. 2008) for various languages.

These two aspects have led some linguists to conclude that syntactic specification should not be part of lexical entries. In the following, two approaches will be discussed which are in line with this conclusion and yet very different, first Neo-Construction Grammar and then Role and Reference Grammar.

\section{Neo-Construction Grammar}

Neo-Construction Grammar (henceforth $\mathrm{N}-\mathrm{CxG}$ ), as developed by Borer (2003, 2005a,b), does not include a lexicon which describes lexical entries as sets of information combining phonological, syntactic and semantic properties. Instead it distinguishes two distinct reservoirs of linguistic items, an encyclopedia on the one hand and a functional lexicon on the other.

The encyclopedia contains encyclopedic items (EIs), also called 'listemes', which are arbitrary sound-meaning pairs not associated with any information concerning syntactic category and argument structure. 'Meaning' here refers to conceptual information of some sort (see below), and 'sound' to abstract phonological representations (cf. Borer 2003: 34).

The functional lexicon includes grammatical formatives represented as head features such as $<\mathrm{p}(\mathrm{a}) \mathrm{st}>$ or $<\mathrm{pl}(\mathrm{ural})>$ or as independent grammatical formatives such as $<$ the, [+def] $>$, called ' $f$-morphs'. In addition it includes category-labeled derivational morphemes such as -ation, -ize or -al.

The categorization of listemes is achieved in two different ways - either by the phrase structure of functional projections or by a morphological structure.

In the first case, listemes forming a conceptual array are inserted into an unmarked and unordered lexical phrasal domain (L-Domain, L-D), providing the set of listemes from which a sentence is constructed, yielding, for example, [L-D listeme ${ }_{1}$, listeme ${ }_{2}$, listeme $_{3}$ ]. The L-D is then merged with an item from the functional lexicon, e.g. <pst>, which specifies one of the listemes with the categorial label $\mathrm{V}$ after it has moved and merged with $<$ pst $>$. If the grammatical formative is a determiner, e. g. $<$ the, $[+\operatorname{def}]>$, then the listeme merged with it is categorized as $\mathrm{N}$. 
Leaving out further details, $\mathrm{N}-\mathrm{CxG}$ in essence claims that there is a fixed set of structures determined by functional nodes and their order which is the same for all human languages and thus universal. Merged with particular functional items and occupying particular positions in these structures, uncategorized listemes become categorized via the properties of the functional nodes dominating them. The following structures and their instantiations - taken from Borer (2005a,b) provide illustrative examples.

(3) and (4) represent assumed structures for proper names and the definite article (Borer 2005a: 80, (28a and b)) respectively:

(3)

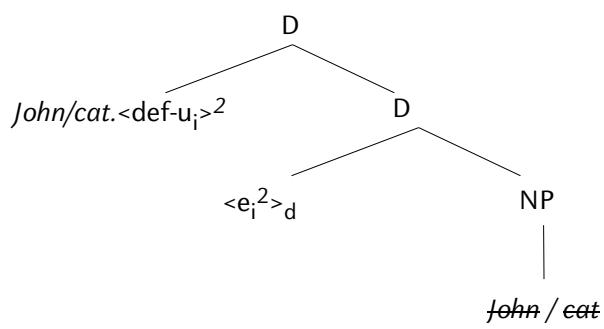

(4)

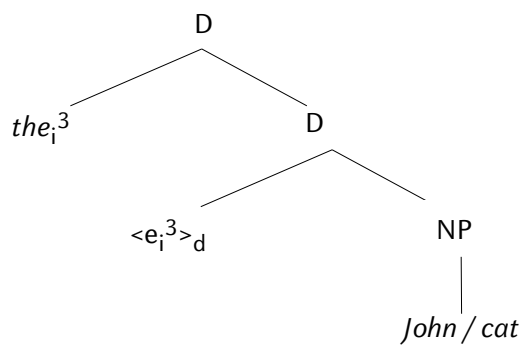

In (3) and (4) proper names and the definite article are analyzed as specifiers of the empty head of $\mathrm{D}$, with the specifiers determining the range of the head. Co-superscription indicates range assignment, whereas the subscripts designate a binding relationship via indexing (cf. ibid.). The specification 'def-u' is short for 'definite and unique' (cf. ibid.: 72).

(5) represents an assumed structure for count nouns (Borer 2005a: 109, (27)) and (6) represents one for mass nouns (ibid.: 110, (28)): 
(5)

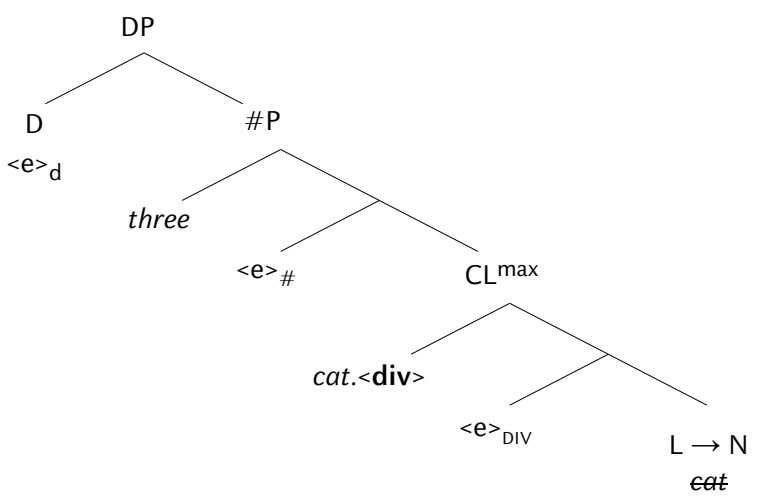

(6)

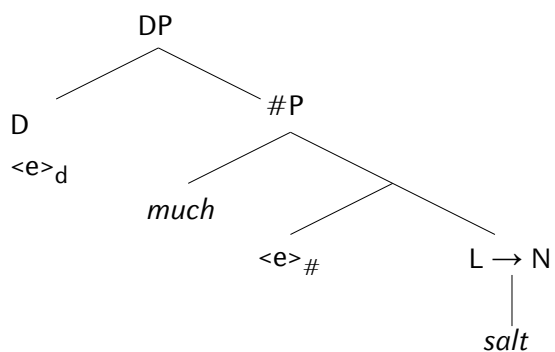

In (5) and (6) \#P represents a Quantity Phrase, which is responsible "for the assignment of quantity to stuff or to division of it" (ibid.: 96). CL ${ }^{\text {max }}$ represents a Classifier Phrase. According to Borer, $\mathrm{CL}^{\max }$ and $\# \mathrm{P}$ are optional. If there is no $\mathrm{CL}^{\max }$, this gives rise to a mass interpretation; if there is no \#P, the result is a non-quantity interpretation (cf. ibid.).

(7), (8) and (9) represent unaccusative (Borer 2005b: 84, (15a)), unergative (ibid: 84, (15b)) and quantity transitive (ibid. $85,(17)$ ) structures respectively: 
Linguistic Categories and the Syntax-Semantics Interface

(7)

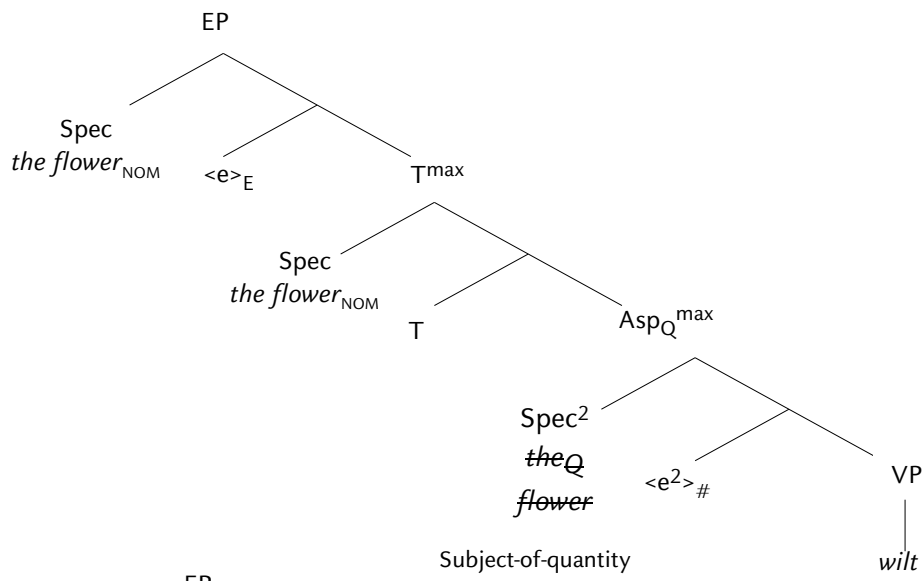

(8)

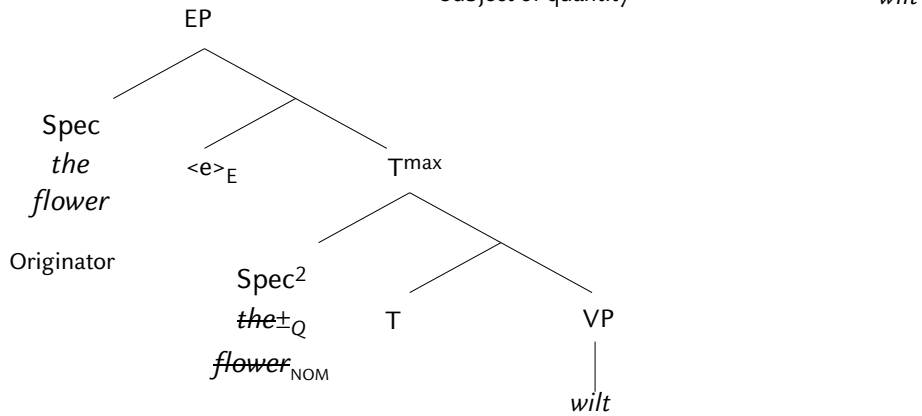

(9)

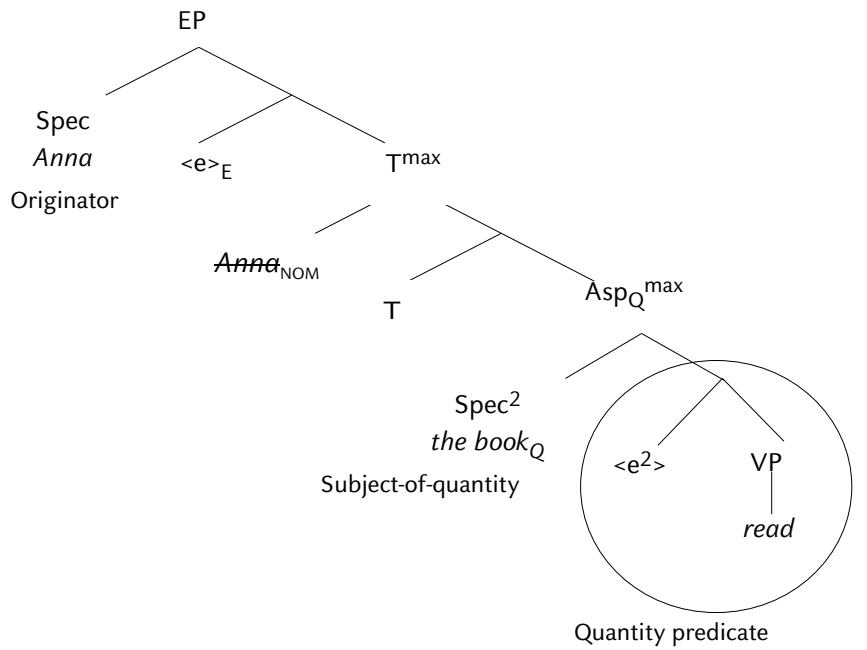


In (7) to (9) EP is an Event Phrase denoting types of events such as states and telic or atelic events. Asp $\mathrm{Q}_{\mathrm{Q} \text { (uantity) }}$ is the syntactic projection for telic interpretation. The DP 'Subject-of-quantity' in the specifier position of $A p_{Q}{ }^{\max }$ is roughly characterized as the 'subject-of-structured change' (cf. ibid:: 72). The DP 'Originator' designates any event participant in the specifier position of EP "which is not otherwise assigned interpretation" (ibid.: 83), i. e. "as subject-of-quantity, or through the mediation of a preposition" (ibid.).

The examples show that one and the same meaning-sound pair or listeme may show up in different structures which then determine whether it is categorized as a proper name or a common noun, as a count noun or a mass noun, or as an unaccusative, an unergative or a transitive verb. In addition, what is categorized here as a verb could just as well be categorized as a noun and vice versa, depending simply on what position and in what structure the listeme occurs. There are no predictions formulated in the encyclopedia.

Categorizing listemes by a morphological structure is accomplished in the following way. In the functional lexicon category-labeled morphemes such as -ation or -al, representing morphological heads, are not only specified for a category of their own but their entries in addition specify the category of the listemes which they take as their morphological complements. Thus, -ation and -al are specified as in (10), representing structures such as those instantiated in (11) for example (cf. Borer 2003: 36 f.):

(10) a. -ation, N, [[v ] _N ]

b. $-\mathrm{al}, \mathrm{A},\left[[\mathrm{N}]_{-} \mathrm{A}\right]$

(11)

a.

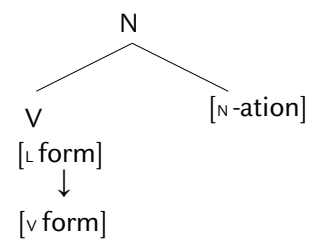

b.

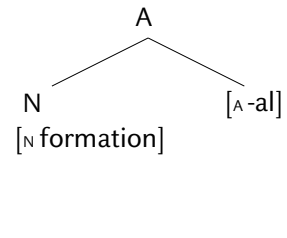

(11a) illustrates the categorization of a non-categorized listeme. In (11b) the listeme is already categorized. In cases like this, the specification of the category in the entry of the morpheme serves as a restriction on word-formation. 
As regards the relationship between the syntactic category and the semantic category of a word, the basic idea of $\mathrm{N}-\mathrm{CxG}$ is that this is not lexically fixed. Instead there is a general concept, such as BOAT or FORM or DOG, paired with a phonological representation to form a listeme which is syntactically categorized in the syntax. But what is a general concept, what is the meaning that count nouns, mass nouns and various verb types share? Whatever this may be, one important implication of this approach is that it is not only the syntactic category of a listeme that is determined by the syntax (or by morphological structure). In addition, whatever distinguishes the meanings of items associated with more than one syntactic category must also be determined by the structure in which they occur. For example, the mass-noun meaning of $d o g$, its count-noun meaning or its transitive-verb meaning must be contributed to its listeme meaning by the particular structure.

As a consequence, $\mathrm{N}-\mathrm{CxG}$ claims that the particular meanings of words are determined by the meanings of their listemes, by the structures they occur in and by the positions they occupy in these structures, with the latter also determining their syntactic category. The interface between the syntactic and semantic categories of words in this approach is thus syntactic structure. This applies to words that are derived from listemes and distinguishes them from items from the functional lexicon, which, in line with the traditional view, are lexically specified for their (grammatical) meanings as well as for their syntactic properties.

\section{Role and Reference Grammar}

Role and Reference Grammar (henceforth RRG) was developed by Van Valin and Foley (Van Valin \& Foley 1980, Foley \& Van Valin 1984) and refined by Van Valin (e. g. 1993, 2005, 2008, 2010, Van Valin \& LaPolla 1997). One of the central goals of RRG is typological adequacy. This determines the design of both its grammar in the narrow sense, i. e. of its syntax, which is semantically based, and of its lexicon. The lexicon contains lexical entries for items attributed to lexical, not syntactic categories, and lexical rules deriving morphologically related words or describing grammatical generalizations.

As opposed to the approaches discussed in sections 2, 3 and 4 above, and only in this respect similar to Borer's approach, in an RRG lexicon lexical entries do not specify any syntactic properties, i. e. neither a syntactic category nor strict 
subcategorization. There is only a semantic representation in the format of logical structures (LS). These differ, depending on whether they represent items assigned to the 'lexical' categories of verb, noun, adjective, preposition or adverb.

LSs of verbs analyze them as Aktionsart classes, as represented in Figure 7:

\begin{tabular}{|c|c|}
\hline Aktionsart class & Logical structure \\
\hline STATE & predicate' $(x)$ or $(x, y)$ \\
\hline ACTIVITY & do' $^{\prime}(x$, predicate' $(x)$ or $\left.(x, y)]\right)$ \\
\hline \multirow[t]{2}{*}{ ACHIEVEMENT } & INGR predicate' $(x)$ or $(x, y)$ or \\
\hline & INGR do' $(x$, [predicate' $(x)$ or $(x, y)])$ \\
\hline \multirow[t]{2}{*}{ SEMELFACTIVE } & SEML predicate' $(x)$ or $(x, y)$ \\
\hline & SEML do' $(x$, [predicate' $(x)$ or $(x, y)])$ \\
\hline \multirow[t]{2}{*}{ ACCOMPLISHMENT } & BECOME predicate' $(x)$ or $(x, y)$ or \\
\hline & BECOME do' (x, [predicate' $(x)$ or $(x, y)])$ \\
\hline ACTIVE ACCOMPLISHMENT & do' $^{\prime}\left(x,\left[\right.\right.$ predicate $\left.\left._{1}^{\prime}(x,(y))\right]\right)$ \& INGR predicate ${ }^{\prime}(z, x)$ or $(y)$ \\
\hline CAUSATIVE & $\alpha$ CAUSE $\beta$, where $\alpha, \beta$ are logical structures of any type \\
\hline
\end{tabular}

Figure 7: Van Valin (2005: 45)

(12) provides some examples of English verbs and their LSs:

(12) a. Bill knew the answer. know' (Bill, answer)

b. John drank beer. do' (John, [drink' (beer)])

c. Bill snored. SEML do' (Bill, [snore' (Bill)])

d. The ice melted. BECOME melted' (ice)

e. The sun melted the ice. [do' (sun, $\emptyset$ )] CAUSE [BECOME melted' (ice)]

The representation of the LSs of nouns follows suggestions made by Pustejovsky (1991a, 1995) in that it gives their qualia structures including the Constitutive Role, the Formal Role, the Telic Role and the Agentive Role of the referents of the nouns. Van Valin provides the following example adapted from Pustejovsky (1995: $85 \mathrm{f}$.) and translated into his own formal representation of LSs (cf. Van Valin 2005: 51):

(13) $\operatorname{novel}(\mathrm{y})$
a. Const: narrative' (y)
b. Form: book' (y), disk' (y)
c. Telic: do' (x, [read' $(\mathrm{x}, \mathrm{y})]$ )
d. Agentive: artifact' (y), do' (x, [write' (x, y)]) \& INGR exist' (y) 
According to Pustejovsky (1991a: 426 f., 1995: 85 f.) and quoted by Van Valin (2005: 51), the various roles are characterized as follows. The Constitutive Role is concerned with "the relation between an object and its constituents, or proper parts", specified as material, weight and parts or components of an object. The Formal Role characterizes "that which distinguishes the object within a larger domain”, which includes orientation, magnitude, shape, dimensionality, color and position. The Telic Role captures the "purpose and function of the object", specified as "the purpose that an agent has in performing an act" and "the built-in function or aim that specifies certain activities". The Agentive Role characterizes "factors involved in the origin or 'bringing about' of an object", specified as creator, artefact, natural kind and causal chain.

Adjectives are described like state predicates, and so are (predicative) prepositions, whereas adverbs are assumed to represent one-place predicates that modify parts of LSs, with temporal adverbs, spatial adverbs or manner and aspectual adverbs modifying different parts.

Semantic representations of sentences are constructed in the lexicon on the basis of the semantic representations of words.

Syntactic representations of sentences are constructed by combining semantically motivated syntactic universal templates, basically consisting of a PREDICATE plus arguments, which form the CORE, and non-arguments, which form the PERIPHERY. These universal templates are complemented by language specific templates stored in a syntactic inventory. Each of the templates represents a partial structure. The universal templates represent the layered structure of the clause, identifying the NUCLEUS, the CORE and the PERIPHERY. Arguments are represented by RPs, i. e. as referential phrases replacing the former NPs. Figure 8 provides an example of an English instantiation of such a structure.

RPs themselves are described as layered structures as well, as shown in Figure 9. The same holds for predicative PPs, which however, are not universal. ${ }^{10}$

One important aspect of RRG syntax is the claim that phrases need not be or are not endocentric. $\mathrm{CORE}_{\mathrm{R}}$ and $\mathrm{RP}$, for example, are not projections of the item that instantiates the $\mathrm{NUC}_{\mathrm{R}}$, and NUC, CORE and CLAUSE are not projections of the item that instantiates the PRED. $\mathrm{NUC}_{R}$ and PRED, as well as all the other categories in the syntactic structures, represent syntactic categories, and items

\footnotetext{
${ }^{10}$ Figure 9 is constructed on the basis of Van Valin \& LaPolla (1997: 57), replacing NP by RP, however.
} 


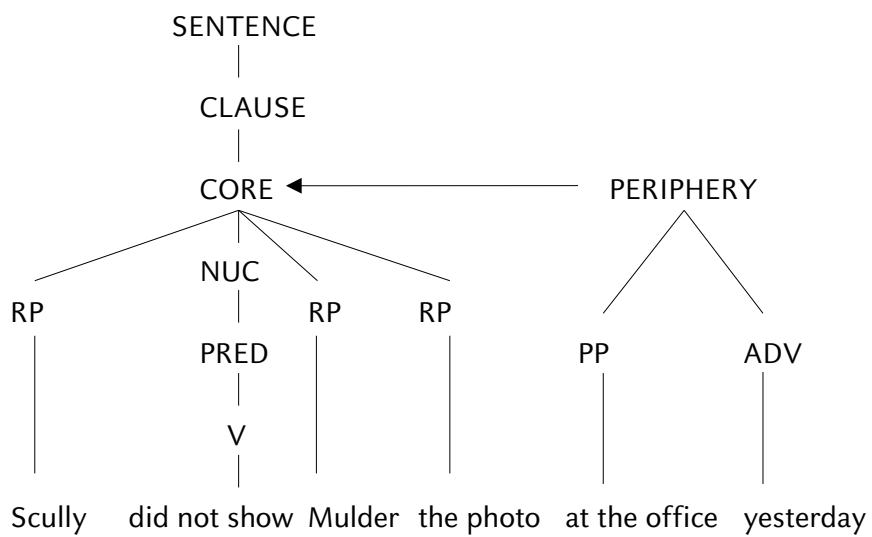

Figure 8: Van Valin (2010: 707)

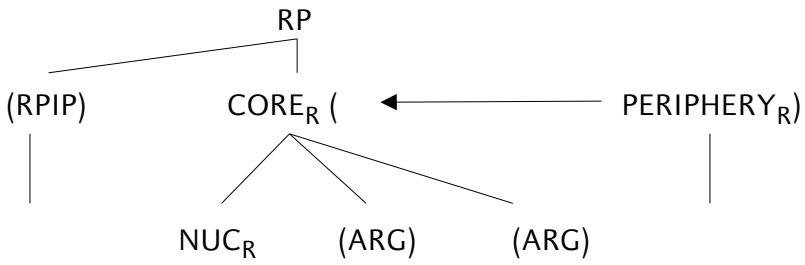

Figure 9: RPs as layered structures

instantiating them are syntactically categorized on the basis of their positions in these structures. There is no corresponding syntactic specification in the lexical entries. As was shown above, lexical entries specify lexical categories such as noun or verb and represent these semantically in the format of LSs. This is intended to capture the claim that for languages like Nootka, Mundari, Tagalog and others the lexical specification of words does not determine their syntactic properties. That is, for example, the same lexical item can instantiate either $\mathrm{NUC}_{\mathrm{R}}$, corresponding to a traditional 'syntactic' noun, or PRED, thus instantiating a traditional 'syntactic' verb.

The question then is how the semantic and the syntactic properties of words are united. In RRG this is achieved by means of a bi-directional linking system that links semantic representations and syntactic structures of sentences, on the one hand mapping semantic representations onto syntactic structures and on the other mapping syntactic structures onto semantic representations. 
In both cases a linking algorithm gives the individual steps with general principles being supplemented by language-specific constructional templates or 'schemas' (Van Valin 2005: 131), which impose language-specific restrictions on otherwise very general principles.

One general principle governing the linking algorithms is the Completeness Constraint, which requires that all of the arguments explicitly specified in the semantic representation of a sentence must be realized in the syntax, and that all of the expressions in the syntactic representation of a sentence must be linked to something in the semantic representation of the sentence (cf. e. g. Van Valin 2010: 732).

Language-type-specific or language-specific aspects of the linking concern the introduction of morpho-syntactic specifications such as finite-verb agreement, case assignment or preposition assignment, which may be formulated as rules or, in case of idiosyncratic language-specific features, represented as constructional schemas.

A prerequisite for the linking is the assignment of macroroles to the arguments in the LS in lexical entries, which provides the basis for deciding which semantic argument is linked with which syntactic argument. Two macroroles, ACTOR and UNDERGOER, are distinguished. Where there is idiosyncrasy, the assignment is specified in a lexical entry. Otherwise it follows the Actor-Undergoer Hierarchy (AUH, cf. ibid.: 717).

Another prerequisite for the linking is the determination of the 'privileged syntactic argument' (PSA), often corresponding to what otherwise is called the 'subject'. It is defined as "a restricted neutralization of semantic roles and pragmatic functions for syntactic purposes" (ibid.: 720).

The linking of a semantic representation to a syntactic representation is described as follows: On the basis of the LSs of lexical items, the semantic representation of a sentence is constructed in the lexicon first. After assigning the macroroles and after determining the PSA selection and assigning morpho-syntactic properties including preposition assignment, an appropriate syntactic template is selected from the syntactic inventory. Finally, elements from the semantic representation are linked to the appropriate positions in the syntactic representation (cf. ibid: 735).

When a syntactic structure is linked to a semantic representation of a sentence, the syntactic representation of the sentence, including its morpho-syntactically 
specified phonetic instantiations of the terminal nodes, is the starting point, with the structure being produced by a parser. The linking algorithm then first extracts the morpho-syntactic information and retrieves the LS of the instantiation of the NUCLEUS from the lexicon. Where possible, the arguments of the LS are assigned macroroles. Finally the syntactic and semantic arguments are linked (cf. ibid:: 736).

Clearly, in this approach the interface between the syntactic and semantic categories of words is provided by the linking algorithms. In lexical entries words are specified for a semantic category but not for a syntactic category. The latter is assigned to them only in the syntax.

\section{The interface between the syntactic and semantic categories of words: lexical entries, syntactic structures or linking rules?}

The major concern of this paper is to evaluate the plausibility of the description of the interface between the syntactic and semantic categories of words in selected linguistic theories. In the preceding sections it has been shown that the theories discussed differ in that they assume that the interface between the two categories is provided either by lexical entries of various types (ST, PPT, HPSG and CxG) or by syntactic structures $(\mathrm{N}-\mathrm{CxG})$ or by linking rules (RRG) ${ }^{11}$ The present section is concerned with the plausibility of these positions. To begin with, the position that lexical entries provide the interface will be discussed, followed by a discussion of the position that it is syntactic structures, and finally that it is linking rules.

\subsection{Lexical entries}

The approaches discussed in sections 2, 3 and 4, i. e. the ST, the PPT, HPSG and $\mathrm{CxG}$, all elaborate the traditional view, which assumes that syntactic and semantic properties are combined in lexical entries and thus determine the syntactic and semantic categories. The lexicon thus specifies whether a particular form can be used both 'nominally' (i. e. as the head of a referring expression) and 'verbally' (i. e. as the head of a predicate), and whether in such a case the meanings asso-

${ }^{11}$ Of course the approaches differ in other respects as well, as was indicated in the previous sections. This, however, is irrelevant for the present discussion. 
ciated with the two uses are related in predictable or unpredictable ways or not at all. This also applies to uses of the same form as a mass or a count noun or as a transitive, unergative or unaccusative verb, and as items of other categories. In all these cases, a syntactic variant of a lexical form and the particular meaning associated with it can be - or is at least supposed to be - described appropriately, and overgeneration or over'construction' is restricted because categorial variability is described only where attested. This restriction is justified because lexical knowledge first and foremost comprises the actual words of a language, leaving the 'lexicalization' of potential words to creativity in accordance with or sometimes violating - lexical rules. ${ }^{12}$ In addition, forms belonging to particular inflectional classes that display features such as gender, declension and conjugation, which are syntactically relevant because they correlate with appropriate or inappropriate syntactic environments, are - or can be - lexically specified as well. According to this view then, it is the lexical entries themselves which provide the interface between the syntactic and semantic categories.

It was shown in section 5 above that two essential criticisms have been leveled at this general approach. First, specifying all the possible syntactic variants and consequently syntactic representations of words in the lexicon requires a large number of lexical entries for many lexical forms, produces redundancies and is therefore uneconomic. And second, parts of speech are not universal and therefore in many languages the syntactic categoryhood of words cannot be identified on the basis of parts of speech in the lexicon, i. e. in isolation, but only in the context of phrases or sentences.

An answer to the first point is that redundancy as such need not be problematic, especially where lexical (rather than syntactic) knowledge is concerned. It is even less so given the fact that in HPSG as well as in $\mathrm{CxG}$ the lexicon is not just a list of isolated lexical entries specifying only idiosyncratic properties, but contains entries of various degrees of generality or specificity related by lexical principles and rules, constraints, schemata or constructions formulating gener-

\footnotetext{
${ }^{12}$ Here I completely disagree with Barner \& Bale (2002), who - defending the approach of Distributed Morphology, which shares essential properties with $\mathrm{N}-\mathrm{CxG}$ - claim that overgeneration is not a problem because "theories of grammar are designed to account for the set of possible grammatical utterances, and nothing more" (ibid: 777 ). Whereas this holds for the syntax of utterances it does not hold for lexical items. This is the reason why the lexicon is considered to be the place where idiosyncratic properties of languages are described. And this is the reason why morphologists since Halle's seminal paper (1973) distinguish between actual and potential words.
} 
alizations concerning the various relationships between lexical items. These can include generalizations concerning zero conversion wherever they are observed, thus avoiding or at least reducing redundancy as well as overgeneralization.

The second point is only valid if parts of speech do indeed represent syntactic categories. But this is a wide-spread misunderstanding, as I have pointed out in various publications (e.g. Rauh 1999, 2000a,b, 2002b, 2010). The syntactic category of words is determined on the basis of shared distribution. A grammar should describe this distribution by means of principles or rules or constraints or constructions and the like which place each word in appropriate positions to construct syntactically well-formed sentences. According to the view underlying the approaches discussed in sections 2, 3 and 4, a grammar can do so only if words are lexically specified for syntactic properties that can be accessed and activated by the principles, rules, constructions, etc. of this grammar. Labels such as $\mathrm{N}, \mathrm{V}, \mathrm{A}$, etc. used in the lexical entries of these approaches represent neither the traditional parts of speech ${ }^{13}$ nor syntactic categories but are cover terms for particular sets of (morpho-)syntactic properties which determine syntactic categories only when supplemented by contextual properties, as is illustrated by the examples in (1) and Figures 1 to 6 above. These supplementary properties include the specification of selection restrictions and strict subcategorization (1), valence and syntactic argument structures (Figure 1) and syntactically relevant specifications such as 'proper -' or 'proper +' for nouns (Figures 2, 3 and 6) and syntactic, semantic and role-based specifications of valence for verbs (Figures 4 and 5). This shows that the lexical representation of the syntactic categories of words includes syntactic properties of the phrases and sentences that can contain them and does not categorize them in isolation, as it does in the case of parts of speech.

Thus, the two criticisms leveled at approaches like those discussed in sections 2, 3 and 4 are at least considerably weakened. As concerns the second criticism, its being weakened is confirmed by the fact that it is a controversial issue among typologists whether there are languages that do not specify words for syntactic properties in the lexicon but only in the syntax, as is claimed for Mundari,

13 This is obvious considering, for example the fact that prepositions in the PPT, following Jackendoff (1973, 1977) and unlike traditional prepositions, are items that can be intransitive or select PP or sentential complements and not always NP/DP complements. Note as well that the infinitive marker to in HPSG is analyzed as representing type verb (cf. the discussion in Rauh 2010: $180 \mathrm{ff}$.). 
Nootka, Samoan, Tagalog and others ${ }^{14}$ (cf. e. g. Evans \& Osada 2005, Peterson 2005, Hengeveld \& Rijkhoff 2005). I will come back to this in section 9. And what is more, it turns out that approaches which suggest that words are lexically specified for syntactic and semantic categories, with their lexical entries providing the interface between the two, avoid problems that $\mathrm{N}-\mathrm{CxG}$ and $\mathrm{RRG}$ are faced with in assuming that syntactic categories are assigned to items only in the syntax.

\subsection{Syntactic structures}

Considering $\mathrm{N}-\mathrm{CxG}$ first, it was shown in section 6 that this approach distinguishes between functional items stored in a functional lexicon and listemes stored in an encyclopedia. Functional items in addition to their (grammatical) meanings are specified for syntactic properties whereas listemes are described as meaning-sound pairs with no syntactic specifications. It is thus predicted that each listeme can occupy any position in a sentence structure that identifies mass nouns, count nouns, proper names, unergative, unaccusative or transitive verbs (and possibly even others), and is syntactically categorized accordingly. The sentence structures themselves are claimed to form a universally fixed set determined by functional nodes and their order. The meaning of a listeme is characterized as a general concept which is associated with the various words that result from the syntactic categorization of the listeme in sentence structures. Particular structures, in turn, contribute to the general concept thus deriving the particular (nominal and verbal) meanings of the various words. In this approach then, it is syntactic structures which provide the interface between semantic and syntactic categories of words.

There are various problems which weaken the appropriateness of this approach. To begin with, it is empirically at least problematic to assume that the meanings of nouns and their verbal counterparts are the same except for aspects contributed by the structures that syntactically categorize their shared listeme. Not only is it entirely unclear how to identify shared 'general concepts' of nouns and verbs, but one prerequisite for the appropriateness of this assumption is that the contribution of a particular structure to the meaning of a listeme is constant. This however is not the case, as the following examples of the simple transitive construction illustrate:

\footnotetext{
${ }^{14}$ Needless to say, this does not mean that it is controversial whether these languages specify words lexically as members of the traditional parts of speech. There is no doubt that they do not.
} 
(14) a. They boated everyone.

b. They dogged everyone

c. They formed everyone.

d. They snailed everyone.

e. They mothered everyone.

f. They fathered everyone.

g. They uncled everyone.

The reason is that the semantic relations between the nominal forms of the items and their verbal counterparts are very different and cannot be predicted by the transitive construction as such. The following possible paraphrases show this:

(14) a'. They transported everyone by boat. / They got everyone on the boat.

b'. They rushed everyone as dogs do.

c'. They got everyone into form.

d'. They removed snails from everyone. / They threw snails at everyone.

e'. They treated everyone like a mother does.

f'. They caused everyone to exist by acting as their fathers. (= They begot everyone.)

g'. They called everyone 'uncle'.

The semantic relationships between nominal and verbal forms must therefore be determined lexically. They may either be idiosyncratic for a particular nominalverbal pair or be shared by unpredictably restricted sets of such pairs. An impressive number of forms exemplifying this have been gathered and analyzed by Karius (1985). Evans (2000) furthermore shows that in various languages the verbal use of kinship terms is restricted to only a few and that these in addition are related to their nominal uses in very different ways. Examples which he gives include to mother, to father and to uncle, with interpretations like those in (14e'), (14f') and (14g'), which follow his suggestions (cf. ibid: 107 f.).

Another point is that this approach in principle claims that listemes could occur in any functional context. Remarks concerning the fact that there may be certain preferences and that these may be specified in the encyclopedia are of little relevance since Borer at the same time points out that these preferences may be overridden in the syntax (cf. Borer 2005a: 77, 106). As it stands then, the grammar to a large extent over'constructs', i. e. a vast amount of sentences 
that are not acceptable are constructed in addition to sentences that are. ${ }^{15}$ As an illustration, consider the sentences that according to Borer (2005a: 29) can derive from the L-Domain [L-D dog, boat, sink]:

(15) a. (The) dog boat(ed) (three) $\operatorname{sink}(\mathrm{s})$

b. (The three) $\operatorname{sink}(\mathrm{s}) \operatorname{boat}(\mathrm{ed})$ (some) $\operatorname{dog}(\mathrm{s})$

c. (The) $\operatorname{sink}(\mathrm{s}) \operatorname{dog}$ (ged) (the) boat

d. (The) boat(s) $\operatorname{dog}$ (ged) (the) sink

e. (The three) $\operatorname{dog}(\mathrm{s}) \operatorname{sank}$ (the) boat

f. (The) boat sank (the) $\operatorname{dog}(\mathrm{s})$

Borer claims that the unacceptable sentences are unacceptable only for reasons of world knowledge, not for grammatical reasons (cf. e. g. Borer 2005a: $11 \mathrm{f}$.). However, there are cases where grammaticality is indeed involved such as when a verb requires a particular syntactic environment, meaning that it is idiosyncratically determined as unaccusative (like arrive), unergative (like dine or bark) or transitive (like see) but is inserted in a structure that does not provide that environment:

(16) a. *The boys arrived the house.

b. *The dog barked the cat.

c. *Bill dined the food.

d. ${ }^{*}$ The crowd saw.

Contrary to fact, N-CxG would have to identify these constructions as grammatically well-formed. It should also be noted that examples (14c) and (14f) above are telic, whereas (14b) and (14e) are not, and (14a) and (14d) are telic only in one of their interpretations. But according to $\mathrm{N}-\mathrm{CxG}$, any of the verbs may occur in a structure like (9) describing telicity.

Another rather serious problem can be seen in the fact that in numerous European languages such as German, the Slavic or the Romance languages nouns are specified for gender. This property is not attributed to listemes in particular syntactic environments but is an idiosyncratic and mostly unpredictable property and thus a typical example of lexical specification. Similarly, there are various

\footnotetext{
${ }^{15}$ Note that a similar criticism is leveled at Goldberg's version of Construction Grammar by Boas (2008). Goldberg's (cf e. g. 1995, 2006) version differs from that of Fillmore and Kay in that she claims that constructions have meanings, predicting that the verbs of a semantic class can all occupy the same position in a given construction and thus assume the meaning of the construction, which Boas shows not to be the case.
} 
languages in which verbs belong to particular conjugation classes and nouns to particular declension classes. Again, these are properties intrinsic to a linguistic item and thus lexical and not the result of syntactic environments. ${ }^{16}$ This means that being categorized as a noun or as a verb at least in these languages is not a matter of syntax. It is determined by properties of the kind mentioned which must be specified before these items enter the syntax. And this renders implausible Borer's assumption that a lexicon of the more traditional kind can be replaced by two reservoirs, a functional lexicon and an encyclopedia, with the latter merely listing meaning-sound pairs with no further specifications.

There are additional problems which I will only mention briefly. Prepositions are classified by Borer as members of the functional lexicon and thus as $f$-morphs (cf. Borer 2005a: 49). However, as pointed out by Rauh in various publications (e. g. 1997, 2002a) and by others, prepositions do not form a homogeneous class. Some of them represent a lexical category comparable to the categories noun, verb and adjective, whereas others behave syntactically more like items of a functional category. Also, what about items subject to processes of grammaticalization that are changing from lexical to functional items and exhibit an intermediate state? As it stands, neither of the two reservoirs is designed to accomodate them. And finally, morphologists are well aware of the fact that word-formation by affixation is subject to various restrictions, which are not captured by the simple specification of a base to which an affix is attached as N, V or A (cf. e. g. Baeskow 2002: 18 ff.; Plag 2003: 59 ff.).

The conclusion to be drawn from this discussion is that assuming with $\mathrm{N}-\mathrm{CxG}$ that it is syntactic structures that provide the interface between the syntactic and semantic categories of words is less plausible than assuming that it is lexical entries, as suggested by the approaches discussed above.

\subsection{Linking rules}

Turning now to RRG, the discussion in section 7 has shown that a distinction is made between lexical and syntactic categories of words, the former including lexical verbs and lexical nouns, the latter including syntactic predicates (PRED) and

\footnotetext{
${ }^{16}$ Aronoff (1994) and others discuss the lexical character of properties like these. Cf. also Don (2004), who on the basis of Dutch illustrates that there are morphological and phonological properties of nouns and verbs which distinguish items of these two categories lexically and that the relationship between the forms in question is not bi-directional. As a result, he claims that this relationship has to be described as (zero) conversion either from noun to verb or from verb to noun.
} 
referential expressions ( $\mathrm{RP}$ with $\mathrm{NUC}_{\mathrm{R}}$ as its head). Lexical categories are represented by logical structures (LS) in lexical entries, with different representations for verbs (Aktionsart classes) and nouns (qualia structures). Semantic representations of sentences are assumed to be constructed in the lexicon, and syntactic representations of sentences, i. e. category-labeled tree structures, to be the result of a parser combining universal and language-specific templates. Bi-directional linking rules, subject to the Completeness Constraint, are designed to link the two types of representations, thus in effect assigning syntactic categories to lexical items, which up to this point lack any syntactic specifications. One reason for this is to allow for both lexical verbs and lexical nouns to instantiate either PRED or $\mathrm{NUC}_{\mathrm{R}}$ and accordingly correspond to a 'syntactic' verb or to a 'syntactic' noun. In this approach then, it is the linking rules that provide the interface between the semantic and syntactic categories of words.

The advantage of this approach is to be seen in the fact that in various languages, but not most European languages, words are - or are claimed to be lexically underspecified and as such (syntactic-) category neutral before entering the syntax, where they may combine with verbal tense markers or with nominal definiteness markers, for example, and thus be syntactically specified as verbs (= syntactic predicates) or nouns (= nuclei of referential phrases). This is where RRG is similar to $\mathrm{N}-\mathrm{CxG}$. RRG differs from $\mathrm{N}-\mathrm{CxG}$ in that it does not assume an encyclopedia listing meaning-sound pairs, with the meaning part representing general concepts claimed to be shared by listemes which are categorized in the syntax either as nouns or verbs. Instead it includes a lexicon with lexical entries distinguishing lexical categories such as $\mathrm{N}$ or $\mathrm{V}$ by representing LSs of Ns as qualia structures and LSs of verbs as classes of Aktionsarten. It also differs from $\mathrm{N}-\mathrm{CxG}$ in that it formulates linking algorithms with specific requirements, among them the Completeness Constraint, which reduces overgeneration. Furthermore, RRG operates with a wide range of semantic and syntactic categories, including operators of various types. As a consequence, certain problems of $\mathrm{N}-\mathrm{CxG}$ are avoided here, but there is one crucial problem to be discussed.

This problem relates to the linking of semantic and syntactic representations and to the claim that lexical verbs may occupy $\mathrm{NUC}_{\mathrm{R}}$ or $\mathrm{RP}$ positions and lexical nouns PRED positions. It is thus central to the present issue. The problem has various facets. Some of these will be discussed here. ${ }^{17}$ The first is the following.

17 Additional facets are discussed in Rauh (2010: 380 ff.). 
Although both are represented as LSs, lexical verbs and lexical nouns are represented differently. Lexical verbs are represented as Aktionsart classes on the basis of logical predicates and arguments, with the latter corresponding to syntactic arguments to which they can be linked accordingly. Lexical nouns are represented as qualia structures which specify a set of roles that characterize the relationship between an object and its constituents on the basis of logical predicates and arguments, with the latter not necessarily corresponding to syntactic arguments and thus violating the Completeness Constraint. The following examples illustrate this. In the first example the PRED position is linked to a lexical verb. Van Valin (2010: 715) analyzes sentence (17a) as an active accomplishment, providing it with the semantic representation in $(17 \mathrm{~b})$ :

(17) a. Carl ate the snail.

b. do' (Carl, [eat' (Carl, snail)]) \& BECOME eaten' (snail)

In this case Carl, instantiating the argument $\mathrm{x}$ in the LS of eat, is assigned the macrorole ACTOR, selected as the PSA (= SUBJECT) and linked to the syntactic argument RP preceding PRED (= ate) in the syntactic representation of (17a). Snail, instantiating the argument y in the LS of eat, is assigned the macrorole UNDERGOER, selected as the OBJECT and linked to the syntactic argument RP following PRED in the syntactic representation of (17a).

In the second example the PRED position is linked to a lexical noun. Imagine a situation where John thought that his life would provide a good story for a novel and he did what is expressed in (18), with novel as an instantiation of PRED:

(18) John noveled his life. ${ }^{18}$

As (13) - repeated here for the reader's convenience - shows, the lexical noun novel is described as a qualia structure specifying four roles, the Constitutive Role, the Formal Role, the Telic Role and the Agentive Role. ${ }^{19}$

(13) novel (y)

Const: narrative' (y)

\footnotetext{
18 According to RRG, this sentence should be well-formed. To the speaker of English, though, a more appropriate verbalization of novel would be novelize, yielding: fohn novelized his life.

${ }^{19}$ It should be noted, though, that according to Pustejovsky not all of the four roles need be specified.
} 


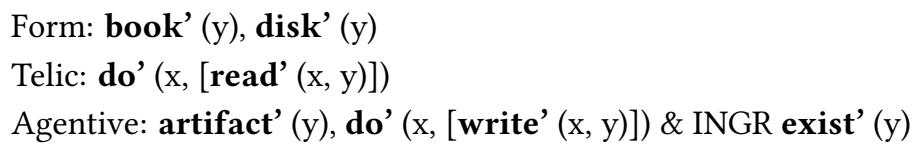

The question that has to be answered is how this structure is linked to the syntactic structure of the sentence in (18). One might assume that the specifications of the four roles are conjoined to form one LS and that the logical arguments $\mathrm{x}$ and $\mathrm{y}$, in a way similar to the process discussed above with respect to (17), are assigned the macroroles ACTOR and UNDERGOER, are selected as SUBJECT (= PSI) and OBJECT, and are linked to the syntactic argument RP preceding PRED (= novel) and to the one following it in the syntactic representation of (18). However, this would not correspond to the interpretation of (18), because y in (13) refers to the novel (cf. novel (y), book' (y), read' (x,y), write' (x, y)) and not to his life which - rather than novel - instantiates the syntactic argument RP following the PRED novel and is interpreted as the UNDERGOER. But there is no semantic argument in the qualia structure of novel designed to semantically represent his life. This shows that there is a semantic argument y which cannot be linked to a syntactic argument, and there is a syntactic argument his life which cannot be linked to a semantic argument. In both cases the Completeness Constraint is violated. It is also at least questionable whether specifications of the Constitutive Role, the Formal Role and the Telic Role should be part of the LS of the syntactic predicate novel, especially if comparable information is not part of the LS of lexical verbs. One might therefore assume that it is only the Agentive Role that characterizes novel in this case. But this would not solve the problem pointed out above. The Completeness Constraint would be violated in just the same way. In addition, in either case a lexical rule would be required to derive the LS of the syntactic predicate novel from its nominal qualia structure, which indicates that it in fact not the case that lexical nouns - as represented in the RRG lexicon - can occupy the syntactic PRED position. Furthermore, this kind of examples raises the question why lexical nouns used as instantiations of PRED and thus syntactically equivalent to lexical verbs in these positions should not be classified and represented like these, i. e. as belonging to one of the Aktionsart classes. The uses of the lexical nouns bottle, fringe and lecture as instantiations of PRED in (19) show that they express an active accomplishment, a state and an activity respectively: 
(19) a. They bottled the wine in less than four days.

b. Grass fringes the creek.

c. The professor lectured for hours.

The question seems especially justified because, as Dowty (1979: $55 \mathrm{ff}$. $)^{20}$ demonstrates, membership of a particular Aktionsart class not only specifies semantic properties but in addition determines various syntactic properties. And finally, why should qualia-structure information not be relevant for the interpretation of sentences if a lexical verb instantiates $\mathrm{NUC}_{\mathrm{R}}$ but be relevant if it is instantiated by a lexical noun?

Another facet of the same problem has to do with the fact already pointed out in connection with the N-CxG approach above, namely that many European languages - and not only these, as Aronoff (1994) shows - distinguish various conjugation classes of verbs and various declension classes of nouns as well as various gender classes of the latter. Classification in all these cases is lexical. Unlike the N-CxG approach, RRG can handle this by specifying the relevant information in the lexical entries, which distinguish between lexical verbs and lexical nouns anyway. ${ }^{21}$ Nevertheless, a problem remains because particular conjugation classes determine the selection of particular morphological tense markers, and particular declension and gender classes determine the selection of particular morphological case and plural markers. ${ }^{22}$ The problem that remains shows up where a lexical verb is linked to a $\mathrm{NUC}_{\mathrm{R}}$ and a lexical noun to PRED. In the first case the lexical verb determines the selection of a particular tense marker, which is not required in this position, but no case or gender marker, of which at least the former is necessary for syntactic reasons. And in the second case the lexical noun determines the selection of a particular case and gender marker, which is not required in a PRED position, but no tense marker. The question that arises here is what determines which particular case and/or gender marker is associated with

${ }^{20}$ Dowty (1979: $60 \mathrm{ff}$.) in addition demonstrates that contrary to Vendler's (1967) assumption it is not verbs that express Aktionsarten and can therefore be analyzed as Aktionsart classes but rather verb phrases. Cf. also Pustejovsky (1991b). Van Valin captures this fact via lexical rules (cf. Van Valin 2013).

${ }^{21}$ This however requires a reformulation of the following statement by Van Valin (2001: 211): "The lexical entry for each verb and other predicating element contains its logical structure, and for most that is all that is required."

${ }^{22}$ Examples of the selection of these markers in various languages are presented and discussed by Aronoff (1994). 
lexical verbs in $\mathrm{NUC}_{\mathrm{R}}$ positions, and which particular tense marker is associated with lexical nouns in PRED positions, and where and how this is determined.

Furthermore, in a language such as English it is not the case that just any lexical verb can instantiate $\mathrm{NUC}_{\mathrm{R}}$ and that just any lexical noun can instantiate PRED, as is predicted by RRG. And finally, like N-CxG, RRG is faced with the situation that nominal and verbal syntactic uses of lexical nouns differ in meaning in ways that cannot be explained by the structures in which they occur. The same holds for nominal and verbal uses of lexical verbs.

It seems then that what at first sight appears to be an advantage of RRG, namely that it distinguishes between lexical and syntactic categories and allows items of various lexical categories to be linked to the same syntactic position turns out to cause a problem, at least for the present conception of this approach. One way out would be to formulate lexical rules that convert lexical representations of nouns into those of lexical verbs to fit the semantic and the syntactic requirements of PRED, and to convert lexical representations of verbs into those of nouns to fit the semantic and the syntactic requirements of $\mathrm{NUC}_{\mathrm{R}}$. And these rules should apply only if the particular conversion is attested. But this would not conform to the general ideas of RRG because one result of including these rules would be that the syntactic categorization of words - or at least its pre-determination - is in fact accomplished in the lexicon and not just a matter of syntactic structures. As it is, the problems pointed out weaken the RRG approach considerably.

\subsection{Conclusion}

In sum then, it turns out to be empirically more plausible to combine syntactic and semantic categories of words in their lexical entries, which provide the interface between the two, because these categories are more intimately related than is assumed in approaches like $\mathrm{N}-\mathrm{CxG}$ and $\mathrm{RRG}$. As a result the approaches discussed in sections 2, 3 and 4 are more plausible in this respect than $\mathrm{N}-\mathrm{CxG}$ and RRG. However, it must be noted that there are essential differences between these approaches. Whereas those discussed in section 2, i. e. ST and PPT, describe the relationship between the syntactic and semantic categories of words only in theory but not in practice, since there is not really any description of semantic properties, ${ }^{23}$ this is different for those discussed in sections 3 and 4, HPSG and

${ }^{23}$ To a certain extent, Katz \& Fodor (1963) can be considered an exception for the ST, and Higginbotham (1985) and Zwarts (1992) for the PPT. 
the Fillmore and Kay version of $\mathrm{CxG}$. As far as descriptive adequacy of the interface between the two types of categories is concerned, these approaches are superior to the others. This is due not least to the fact that in these approaches the lexicon is not simply a list of idiosyncratic properties of lexical items but includes lexical rules or constructions that capture generalizations relating lexical entries of various kinds.

\section{Cross-linguistic differences?}

Predictable criticisms of this discussion and the conclusion suggested above are that my argumentation is based only on English and properties of (mostly) IndoEuropean languages $^{24}$ and that this does not hold for languages like Mundari, Samoan, Nootka, Tagalog and the like, which do not lexically specify the syntactic properties of words, which therefore can be used in either 'nominal' or 'verbal' syntactic contexts, for example. The first criticism is true, but the second needs to be discussed. Not having a native-speaker like knowledge of any of these languages nor even having studied parts of them, I can only refer to and rely on published views. And as revealed by the controversial discussion of the Austronesian language Mundari, which is spoken in India, there are doubts about the claim that languages like this one do not lexically specify forms that can be used nominally, i. e. as heads of referring expressions, or verbally, i. e. as heads of syntactic predicates. Contrary to previous claims, Evans \& Osada (2005) argue that they do, whereas Peterson (2005) as well as Hengeveld \& Rijkhoff (2005), commenting on the paper by Evans \& Osada, defend previous claims and argue that they do not.

Evans \& Osada (2005) base their argumentation on three criteria which have to be fulfilled to classify a language as 'flexible' in the sense of Hengeveld (e. g. 1992) and thus as not distinguishing verbs and nouns (and in addition adjectives and adverbs, an aspect which is not discussed here) in the lexicon. These criteria are (1) distributional equivalence that is fully bi-directional, (2) explicit semantic compositionality for arguments and predicates, and (3) exhaustiveness. The first criterion requires that members of a 'flexible' class must have identical distribu-

\footnotetext{
${ }^{24}$ Note though, that Aronoff (1994) includes Arapesh and Yimas, two languages of Papua New Guinea, and also various Semitic languages in his discussion of syntactically relevant nominal and verbal inflectional classes.
} 
tions, i. e. both 'object' words, from a European perspective lexically identified as 'nouns', and 'action words', identified from this perspective as 'verbs', must be equally acceptable as syntactic predicates and as (heads of) syntactic arguments. According to the third criterion, this must be the case for all 'nouns' and all 'verbs'. The second criterion requires that the semantic difference between the same form in different syntactic positions, i. e. as a predicate and as an argument, must be fully attributable to the function of that position. According to the investigations of Evans and Osada, Mundari, like other languages of the Munda family, does not fulfill either of these criteria. Their resulting "verdict" is "that Munda clearly distinguishes nouns from verbs, though (like English, Chinese and many other languages) it has widespread zero conversion" (2005: 384). In addition they state that

though it is clear that in many languages there is a "weak" noun-verb distinction, we do not believe there exist - as yet - attested cases of languages lacking a noun-verb distinction altogether, according to the highest standards of description and argumentation. (ibid.)

Peterson's (2005) reaction to Evans \& Osada is mostly based on Kharia, another Munda language. His main points are that all the lexical morphemes in this language are 'precategorial' and that the meaning relationship between their nominal and verbal uses in syntactic structures is productive and predictable in that if a meaning of the nominal use is ' $\mathrm{X}$ ', then the meaning of its verbal counterpart is 'turn (something) into X' or 'become X'. Restrictions are said to be only semantic. A brief look at Mundari leads him to the conclusion that the situation in this language is just as it is in Kharia. In a subsequent paper (2007), Peterson goes into more detail and finds his view on Kharia confirmed.

Hengeveld \& Rijkhoff (2005) first point out various flaws in Evans \& Osada's discussion of Mundari and then defend the view that this language, like others, is flexible, meaning that (1) there is no lexical determination of syntactic properties, and (2) the meanings of lexical forms are vague. Concerning the latter aspect, they claim:

Both the verbal and nominal sense of a flexible lexeme are contained in its (vague) semantics and the context only highlights the meaning components that are already there, giving the flexible item its verbal or nominal flavour. (ibid: 415)

I do not feel able to decide who is right and who is wrong in this controversy. I can only point out what the consequences are in each of the two cases. If 
Evans \& Osada are right, then nothing needs to be added to my conclusion drawn above: Approaches which describe lexical entries as the interface between the syntactic and semantic categories of words are more plausible than approaches which consider this interface to be either syntactic structures or linking rules. And this then holds cross-linguistically. If Peterson and Hengeveld \& Rijkhoff (and others) are right, then different solutions are necessary for flexible and for 'rigid' languages like the Indo-European ones, because the latter, according to Hengeveld (1992) and Hengeveld \& Rijkhoff (2005: 406 f.), are unlike Mundari and other languages and do lexically specify items for syntactic properties. This is a view shared by Himmelmann (2008), who classifies languages on the basis of whether they specify lexical as well as syntactic categories in the lexicon, claiming that Indo-European languages do but languages like Tagalog do not (cf. ibid.: 264). According to him, the latter languages specify syntactic categories only in the syntax. In this second case then, the conclusion above holds only for Indo-European languages and others that behave like them, whereas for Mundari, Tagalog and other languages it is more appropriate for syntactic structures or linking rules to provide the interface between the syntactic and semantic categories of words. It has to be noted though that in contrast to the RRG approach but like $\mathrm{N}-\mathrm{CxG}$, Hengeveld \& Rijkhoff claim that no semantic distinction between lexical verbs and lexical nouns is justified. In the lexicon there is just one vague meaning shared by forms that can be used either verbally or nominally.

I leave it to future research to decide what the consequences to be drawn from this discussion must be. Nevertheless I will conclude with a personal comment and an open question. There is no doubt that words in languages like Mundari, Nootka, Tagalog and others are not lexically specified for the traditional parts of speech such as noun, verb, adjective, etc. and the syntactic properties associated with these. But I find it hard to imagine that they are not lexically specified for any syntactic properties, including contextual or distributional ones ${ }^{25}$, for example, that a word can be used in positions not available for one and the same word in Indo-European languages. If they are not, how then do speakers of these

${ }^{25}$ As I have pointed out in various publications, it is often the case that parts of speech are confused with syntactic categories (cf. e. g. Rauh 2010, esp. chaps. 1, 2, 9.2 and 10). Parts of speech have certain syntactic consequences but they are not syntactic categories. In this context it should be noted that Hengeveld's categorization of language types, which is included in the discussion above, is based on his identification of parts of speech, not of syntactic categories. 


\section{References}

languages know how to use a form appropriately in order to construct wellformed sentences?

\section{References}

Aronoff, M. 1994. Morphology by itself. Stems and inflectional classes. Cambridge, MA: The MIT Press.

Baeskow, H. 2002. Abgeleitete Personenbezeichnungen im Deutschen und Englischen. Kontrastive Wortbildungsanalysen im Rahmen des Minimalistischen Programms und unter Berücksichtigung sprachhistorischer Aspekte. Berlin: Mouton de Gruyter.

Barner, D. \& A. Bale. 2002. No nouns, no verbs: psycholinguistic arguments in favor of lexical underspecification. Lingua 112: 771-791.

Bhat, D. N. S. 2000. Word classes and sentential function. In P. M. Vogel \& B. Comrie (eds.), Approaches to the typology of word classes, 47-64. Berlin: Mouton de Gruyter.

Boas, H. C. 2008. Determining the structure of lexical entries and grammatical constructions in construction grammar. Annual Review of Cognitive Linguistics 6: $113-144$.

Borer, H. 2003. Exo-skeletal vs. endo-skeletal explanations. In J. Moore \& M. Polinsky (eds.), The nature of explanation in linguistic theory, 31-67. Chicago: CSLI Publications.

Borer, H. 2005a. Structuring sense. In name only. Oxford: Oxford University Press.

Borer, H. 2005b. Structuring sense. The normal course of events. Oxford: Oxford University Press.

Chomsky, N. 1965. Aspects of the theory of syntax. Cambridge, MA: The MIT Press.

Chomsky, N. 1981. Lectures on government and binding. Dordrecht: Foris Publications.

Chomsky, N., \& H. Lasnik. 1993. Principles and parameters theory. In J. Jacobs, A. von Stechow, W. Sternfeld \& T. Vennemann (eds.), Syntax: an international handbook of contemporary research, 506-569. Berlin: Mouton de Gruyter.

Clark, E. V. \& H. Clark. 1979. When nouns surface as verbs. Language 55: 767-811. Don, J. 2004. Categories in the lexicon. Linguistics 42: 931-956.

Dowty, D. R. 1979. Word meaning and Montague Grammar. The semantics of verbs and times in generative semantics and in Montague's PTQ. Dordrecht: Reidel. 
Evans, N. 2000. Kinship verbs. In P. M. Vogel \& B. Comrie (eds.), Approaches to the typology of word classes, 103-172. Berlin: Mouton de Gruyter.

Evans, N. \& T. Osada. 2005. Mundari: the myth of a language without word classes. Linguistic Typology 9: 351-390.

Fillmore, C. J. 1999. Inversion and constructional inheritance. In G. Webelhuth, J.-P. Koenig \& A. Kathol (eds.), Lexical and constructional aspects of linguistic explanation, 113-128. Stanford: CSLI Publications.

Fillmore, C. J. \& P. Kay. 1993. Construction Grammar Coursebook. Ms. University of California, Berkeley.

Foley, W. A. \& R. D. Van Valin, Jr. 1984. Functional syntax and universal grammar. Cambridge: Cambridge University Press.

Gil, D. 1995. Parts of speech in Tagalog. In M. Alves (ed.), Papers from the Third Annual Meeting of the Southeast Asian Linguistics Society, 67-90. Tempe, Arizona.

Goldberg, A. 1995. Constructions. A construction grammar approach to argument structure. Chicago: University of Chicago Press.

Goldberg, A. 2006. Constructions at work. Oxford: Oxford University Press.

Halle, M. 1973. Prolegoma to a theory of word-formation. Linguistic Inquiry 4: 3-16.

Hengeveld, K. 1992. Parts of Speech. In M. Fortescue, P. Harder \& L. Kristoffersen (eds.), Layered structure and reference in a functional perspective: papers from the Functional Grammar Conference in Copenhagen 1990, 29-55. Amsterdam \& Philadelphia: John Benjamins Publishing Company.

Hengeveld, K. \& J. Rijkhoff. 2005. Mundari as a flexible language. Linguistic Typology 9: 406-431.

Higginbotham, J. 1985. On semantics. Linguistic Inquiry 16: 547-593.

Himmelmann, N. P. 2008. Lexical categories and voice in Tagalog. In S. Musgrave $\&$ P. Austin (eds.), Voice and grammatical relations in Austronesian languages, 247-293. Stanford: CSLI Publications.

Jackendoff, R. S. 1973. The base rules for prepositional phrases. In S. Anderson \& P. Kiparsky (eds.), A Festschrift for Morris Halle, 345-356. New York: Holt, Rinehart and Winston.

Jackendoff, R. S. 1977. X'-syntax: a study of phrase structure. Cambridge, MA: The MIT Press. 


\section{References}

Karius, I. 1985. Die Ableitung der denominalen Verben mit Null-Suffigierung im Englischen. Tübingen: Niemeyer.

Katz, J. \& J. Fodor. 1963. The structure of a semantic theory. Language 39: 170-210.

Kay, J. 2002. An informal sketch of a formal architecture for construction grammar. Grammars 5: 1-19.

Kay, P. \& C. J. Fillmore. 1999. Grammatical constructions and linguistic generalizations: the what's X doing Y? construction. Language 75: 1-33.

Kuhn, J. 2007. Interfaces in constraint-based theories of grammar. In G. Ramchand \& C. Reiss (eds.), The Oxford handbook of linguistic interfaces, 613-650. Oxford: Oxford University Press.

Levine, R. D. \& W. D. Meurers. 2006. Head-driven phrase structure grammar: linguistic approach, formal foundations, and computational realization. In K. Brown (ed.), The encyclopedia of language and linguistics, second edition, 237252. Oxford: Elsevier Science Publisher B.V.

Mosel, U. \& E. Hovdhaugen. 1992. Samoan reference grammar. Oslo: Scandinavian University Press.

Müller, S. 2010. Grammatiktheorie. Tübingen: Stauffenburg.

Peterson, J. 2005. There's a grain of truth in every "Myth", or, why the discussion of lexical classes in Mundari isn't quite over yet'. Linguistic Typology 9: 391441.

Peterson, J. 2007. Languages without nouns and verbs? An alternative to lexical classes in Kharia. In C. P. Masica (ed.), Old and new perspectives on South Asian languages: grammar and semantics. Papers growing out of the Fifth International Conference on South Asian Linguistics (ICOSAL-5), 274-303.

Plag, I. 2003. Word-formation in English. Cambridge: Cambridge University Press.

Pollard, C. \& I. A. Sag. 1987. Information-based syntax and semantics. Vol. 1: fundamentals. Stanford: CSLI Publications.

Pollard, C. \& I. A. Sag. 1994. Head-driven phrase structure grammar. Chicago: University of Chicago Press.

Pustejovsky, J. 1991a. The generative lexicon. Computational Linguistics 17: 409441.

Pustejovsky, J. 1991b. The syntax of event structure. Cognition 41: 47-81.

Pustejovsky, J. 1995. The generative lexicon. Cambridge, MA: The MIT Press.

Rauh, G. 1997. Englische Präpositionen zwischen lexikalischen und funktionalen Kategorien. In E. Löbel \& G. Rauh (eds.), Lexikalische Kategorien und Merk- 
male, 125-167. Tübingen: Max Niemeyer Verlag.

Rauh, G. 1999. Adverb oder Präposition? Von der Notwendigkeit einer Abgrenzung von Wortarten und grammatischen Kategorien und der Gefahr einer terminologischen Falle. In E. Eggers, J. Becker, J. Udolph \& D. Weber (eds.), Florilegium Linguisticum. Festschrift für Wolfgang P. Schmid zum 70. Geburtstag, 367-392. Frankfurt/M: Lang.

Rauh, G. 2000a. Don't Call it "X"! or: why X does not represent grammatical categories. In H. Janßen (ed.), Verbal Projections, 1-21. Tübingen: Niemeyer.

Rauh, G. 2000b. Wi(e)der die Wortarten! Zum Problem linguistischer Kategorisierung. Linguistische Berichte 184: 485-507.

Rauh, G. 2002a. Prepositions, features and projections. In H. Cuyckens \& G. Radden (eds.), Perspectives on prepositions, 3-23. Tübingen: Niemeyer.

Rauh, G. 2002b. Word classes as prototypical categories. In S. Scholz, M. Klages, E. Hantson \& U. Römer (eds.), Context and cognition. Papers in honour of WolfDietrich bald's 60th birthday, 259-270. München: Langenscheidt-Longman $\mathrm{GmbH}$.

Rauh, G. 2010. Syntactic categories. Their identification and description in linguistic theories. Oxford: Oxford University Press.

Sag, I. A., T. Wasow \& E. M. Bender. 2003. Syntactic theory. A formal introduction, second edition. Stanford: CSLI Publications.

Schachter, P. 1985. Parts of speech systems. In T. Shopen (ed.), Language typology and syntactic description, 3-61. Cambridge: Cambridge University Press.

Swadesh, M. 1939. Nootka internal syntax. International fournal of American Linguistics 9: 77-102.

Van Valin, R. D., Jr. 1993. A synopsis of role and reference grammar. In R. D. Van Valin, Jr. (ed.), Advances in role and reference grammar, 1-164. Amsterdam and Philadelphia: John Benjamins Publishing Company.

Van Valin, R. D., Jr. 2001. An introduction to syntax. Cambridge: Cambridge University Press.

Van Valin, R. D., Jr. 2005. Exploring the syntax-semantics interface. Cambridge: Cambridge University Press.

Van Valin, R. D., Jr. 2008. RPs and the nature of lexical and syntactic categories in role and reference grammar. In R. D. Van Valin, Jr. (ed.), Investigations of the syntax-semantics-pragmatics interface, 161-178. Amsterdam and Philadelphia: John Benjamins Publishing Company. 


\section{References}

Van Valin, R. D., Jr. 2010. Role and reference grammar as a framework for linguistic analysis. In B. Heine and H. Narrog (eds.), The Oxford handbook of linguistic analysis, 703-738. Oxford: Oxford University Press.

Van Valin, R. D., Jr. 2013. Lexical representation, co-composition, and linking syntax and semantics. In J. Pustejovsky et al. (eds.), Advances in Generative Lexicon theory, 67-107. Dordrecht: Kluwer.

Van Valin, R.D., Jr. \& W. A. Foley. 1980. Role and reference grammar. In E. A. Moravcsik \& J. R. Wirth (eds.), Syntax and semantics Vol. XIII: current approaches to syntax, 329-352. New York: Academic Press.

Van Valin, R. D., Jr. \& R. LaPolla. 1997. Syntax. Structure, meaning, and function. Cambridge: Cambridge University Press.

Vendler, Z. 1957 (1967). Linguistics in philosophy. Ithaca: Cornell University Press.

Vogel, P. M. \& B. Comrie (eds.) 2000. Approaches to the typology of word classes. Berlin: Mouton de Gruyter.

Zwarts, J. 1992. X'-syntax - X'-semantics. On the interpretation of functional and lexical heads. Utrecht: OTS Dissertation Series.

\section{Author}

Gisa Rauh

University of Wuppertal

rauh@uni-wuppertal.de 
